\title{
Association of Perceived Stress and Gastrointestinal Symptoms in College Students: A Systematic Review
}

\author{
Hamna Akram Ameer, Sushil Pokhrel, Maurice H. Dick, Nabeel Riaz Ahmed, Arowa Abdelgadir, \\ Vaishnavi Kuilkarni, Abanti Chatterjee, Safeera Khan
}

California Institute of Behavioral Neurosciences and Psychology, California, USA

Email: hamnaakameer@gmail.com

How to cite this paper: Ameer, H.A., Pokhrel, S., Dick, M.H., Ahmed, N.R., Abdelgadir, A., Kuilkarni, V., Chatterjee, A. and Khan, S. (2021) Association of Perceived Stress and Gastrointestinal Symptoms in College Students: A Systematic Review. Open Journal of Gastroenterology, $11,275-284$.

https://doi.org/10.4236/ojgas.2021.1112027

Received: November 8, 2021

Accepted: December 20, 2021

Published: December 23, 2021

Copyright $\odot 2021$ by author(s) and Scientific Research Publishing Inc. This work is licensed under the Creative Commons Attribution International License (CC BY 4.0).

http://creativecommons.org/licenses/by/4.0/

\begin{abstract}
Stress and anxiety are common entities in college students, and only a handful of students can handle these stressors appropriately, while others may show physical signs and symptoms. The main purpose of this systematic review was to examine the association between perceived stress and gastrointestinal symptoms. A detailed search was conducted using five databases: PubMed, Research Gate, Science Direct, American Journal of Gastroenterology, and Google scholar. Ten papers were finalized after the application of various inclusion and exclusion criteria. The Newcastle Ottawa scale was used to evaluate the quality of the included articles as all the included articles were cross-sectional studies. The systematic review of these finalized articles found that most studies revealed the prevalence of gastrointestinal symptoms in college students and were linked to perceived stress.
\end{abstract}

\section{Keywords}

Gastrointestinal Symptoms, Perceived Stress

\section{Introduction}

Around $45 \%$ of American college students claimed to undergo "more than average stress." In comparison, 33\% of students reported "average stress," and 12.7\% said it is "tremendous stress." Eight out of ten university students in the UK reported stress and/or anxiety in school [1]. Stress is a common word heard in our daily conversations. The non-specific response of the body to demands placed on it or distressing occurrences in the environment is classified as stress. It is a process by which we perceive and react with environmental hazards and difficulties, not merely a stimulus or a response [2]. We are all stressed throughout 
the day for some reason or the other, and we try and relax in different ways. However, stress in college students is something easily overseen. Due to the multiple internal and external expectations placed on students' shoulders, stress has become a component of their academic lives [3]. Many believe that stress comes in a package with acceptance into college.

University students feel several symptoms and health complaints. Back and shoulder pains, a variety of headaches, a variety of gastrointestinal symptoms, psychological symptoms, psychiatric episode(s), and mental health outcomes such as depression and anxiety, difficulty sleeping, and circulatory/breathing complaints (e.g., dyspneic symptoms, tachycardia, excessive perspiration, and menstruation disorders) are all examples of stress-related complaints [4]. Symptoms/complaints of this nature have tremendous consequences for these young adults, impacting students' academic performance. In general, worsening in students' health can have an impact on their ability to learn, academic performance, and goal attainment [4].

Regardless of the fact that college students are under a lot of stress, there hasn't been much research on how stress affects their bodily reactions, such as gastrointestinal issues. Gastrointestinal (GI) problems, which affect a large percentage of the world's population, lead to increased healthcare consumption and have a detrimental influence on everyday activities and quality of life [5]. Norton et al. reported that "GI symptoms were diagnosed in $51.2 \%$ of the 127 university students in Canada, and functional dyspepsia (22.8\%), dyschezia (20.5\%), and functional heartburn (19.7\%) were the most frequently diagnosed disorders [6]. The visceral nerve system, the immunological system, and the hypothalamic-pituitary-adrenal axis all play a role in gastrointestinal motility, which is modulated by stress" [7].

This systematic review aims to find the association between perceived stress and gastrointestinal symptoms in college students. If the association of perceived stress and gastrointestinal symptoms is proved, students can find other ways of controlling these symptoms instead of using powerful drugs. Alternative ways like seeing a counselor, enjoying a favorite hobby, or doing a favorite sport could help students to reduce their level of stress and thereby reduce the unpleasant symptoms

\section{Method}

We used the Preferred Reporting Items for Systematic Reviews and Meta-Analyses (PRISMA) guidelines, 2020 to write this systematic review.

\subsection{Sources and Search Strategies}

The articles relevant to the topic were found using the below-mentioned databases and search strategies (Table 1 and Table 2).

\subsection{Eligibility}

Eligible review articles were identified after screening and applying the inclusion/exclusion criteria. 
Table 1. Keywords and the combinations according to different databases.

\begin{tabular}{ll}
\hline \multicolumn{1}{c}{ Source } & \multicolumn{1}{c}{ Keywords used } \\
\hline $\begin{array}{l}\text { PubMed } \\
(\mathrm{MESH})\end{array}$ & $\begin{array}{l}\text { Perceived stress OR Self-perceived stress OR psychological } \\
\text { stress OR mental stress OR “Stress, Psychological” [Majr] }\end{array}$ \\
& $\begin{array}{l}\text { AND Gastrointestinal symptoms OR GI manifestation OR } \\
\text { Signs and Symptoms, "Digestive/psychology" [Majr] }\end{array}$ \\
\hline Research Gate & $\begin{array}{l}\text { Perceived stress OR Self-perceived stress OR psychological } \\
\text { stress OR mental stress AND Gastrointestinal symptoms OR } \\
\text { GI manifestation. }\end{array}$ \\
\hline Science Direct & Stress AND GERD in college students \\
\hline $\begin{array}{l}\text { American Journal } \\
\text { of Gastroenterology }\end{array}$ & Psychological stress AND GI symptoms \\
\hline Google Scholar & Perceived stress AND GI symptoms \\
& Perceived stress AND college students \\
\hline
\end{tabular}

Table 2. Eligible review articles.

\begin{tabular}{cc}
\hline Inclusion criteria & Exclusion criteria \\
\hline Articles from the last ten years & Unpublished literature \\
In the English language & Grey literature \\
Articles relevant to the question & Articles in foreign languages \\
Focusing on college students & \\
Abstracts and full texts & \\
\hline
\end{tabular}

\section{Results}

We used the following five databases were used to collect relevant articles: PubMed, Research Gate, Science Direct, American Journal of Gastroenterology, and Google Scholar. Initially, 23,598 articles were found, of which duplicates (n $=500)$ and ineligible $(\mathrm{n}=8735)$ were removed by automation tools. The remaining 14,363 articles were screened by title/abstract and assessed for eligibility, and a total of 14,338 articles were excluded. A total of 15 articles, all cross-sectional studies were thoroughly read, and five articles were excluded due to poor quality. The Newcastle Ottawa Scale was used to assess the studies' quality.

The PRISMA flow diagram is shown in Figure 1.

Summaries of the included studies are explained in Table 3.

The assessment of the quality of the studies using the Newcastle Ottawa Scale is explained in Table 4.

\section{Discussion}

This section discusses the stressors in students' life, frequency of symptoms by the level of stress, the most common gastrointestinal symptoms students complain of, and Asian vs. western students, the difference. 
Table 3. Summary of the included cross-sectional studies.

\begin{tabular}{|c|c|c|c|c|c|}
\hline Author & $\begin{array}{c}\text { Year of } \\
\text { publication }\end{array}$ & Country & $\begin{array}{l}\text { Number of } \\
\text { participants }\end{array}$ & GI symptoms & Outcomes \\
\hline $\begin{array}{c}\text { El Ansari et } \\
\text { al. [4] }\end{array}$ & 2014 & $\begin{array}{c}\text { UK } \\
\text { Egypt }\end{array}$ & 6977 & $\begin{array}{l}\text { Diarrhea } \\
\text { Constipation } \\
\text { Abdominal problems }\end{array}$ & $\begin{array}{l}\text { With increasing levels of perceived stress, the } \\
\text { frequency of symptoms increased. More } \\
\text { females reported more stress than males. } \\
\text { Younger students were more prone to suffer } \\
\text { from stress. } \\
\text { Effective coping/preventive mechanisms need } \\
\text { to be considered by students to minimize the } \\
\text { level of stress and its impact on health. }\end{array}$ \\
\hline Lee et al. [5] & 2011 & Korea & 715 & $\begin{array}{l}\text { Upper dysmotility } \\
\text { Bowel symptoms }\end{array}$ & $\begin{array}{l}\text { Students who experienced higher perceived } \\
\text { stress complained of more than one } \\
\text { gastrointestinal symptom. } \\
\text { No significant gender difference. } \\
\text { High levels of perceived stress are regarded as a } \\
\text { threat to gastrointestinal symptoms, and } \\
\text { effective interventions need to be developed to } \\
\text { reduce the stress the students' encounter }\end{array}$ \\
\hline
\end{tabular}

\begin{tabular}{|c|c|c|c|c|c|}
\hline Jahan et al. [7] & 2020 & Oman & 81 & $\begin{array}{l}\text { Post-meal fullness } \\
\text { Bloating } \\
\text { Abdominal pain } \\
\text { Diarrhea } \\
\text { Constipation } \\
\text { Irritable bowel syndrome }\end{array}$ & $\begin{array}{l}\text { There is a link between stress and two signs of } \\
\text { upper dysmotility. } \\
\text { Gastrointestinal symptoms are more prevalent } \\
\text { among females than males. }\end{array}$ \\
\hline Nur et al. [8] & 2015 & Turkey & 449 & $\begin{array}{l}\text { Upper dysmotility } \\
\text { Bowel symptoms }\end{array}$ & $\begin{array}{l}\text { Gastrointestinal symptoms are prevalent } \\
\text { among students with a high level of perceived } \\
\text { stress. }\end{array}$ \\
\hline $\begin{array}{l}\text { Balmus et al. } \\
\text { [9] }\end{array}$ & 2019 & Rome & 50 & $\begin{array}{l}\text { Functional } \\
\text { gastrointestinal } \\
\text { symptoms }\end{array}$ & $\begin{array}{l}\text { Stress-exposed students reported a higher } \\
\text { occurrence of gastrointestinal symptoms. } \\
\text { Females experienced more stress and } \\
\text { gastrointestinal symptoms. } \\
\text { Perceived stress levels and gastrointestinal } \\
\text { symptoms decreased with age. } \\
\text { Functional gastrointestinal symptoms are } \\
\text { almost certainly a reaction to stress. }\end{array}$ \\
\hline Chu et al. [10] & 2012 & China & 5000 & $\begin{array}{l}\text { Functional dyspepsia } \\
\text { Irritable bowel syndrome } \\
\text { Functional constipation }\end{array}$ & $\begin{array}{l}\text { Psychological disorders such as anxiety provide } \\
\text { a significant risk for irritable bowel syndrome. } \\
\text { The symptoms were mostly seen in female } \\
\text { students. }\end{array}$ \\
\hline
\end{tabular}

The stressors can be academic, psychosocial, or health-related.

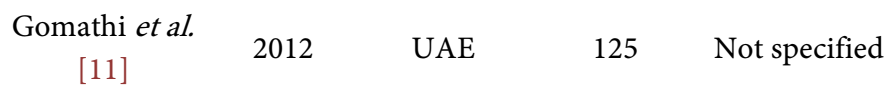

No significant association between academic stress and health complaints or gastrointestinal symptoms 


\section{Continued}

\begin{tabular}{|c|c|c|c|c|c|}
\hline Awadalla [12] & 2019 & $\begin{array}{l}\text { Saudi } \\
\text { Arabia }\end{array}$ & 2878 & $\begin{array}{l}\text { Gastroesophageal reflux } \\
\text { symptoms }\end{array}$ & $\begin{array}{l}\text { Gastroesophageal reflux disease is highly } \\
\text { prevalent among college students, especially } \\
\text { males. }\end{array}$ \\
\hline Chu et al. [13] & 2015 & $\begin{array}{l}\text { Germany } \\
\text { China }\end{array}$ & 5159 & $\begin{array}{l}\text { Diarrhea } \\
\text { Constipation } \\
\text { Stomach trouble }\end{array}$ & $\begin{array}{l}\text { Many students experience one or more health } \\
\text { complaints besides gastrointestinal symptoms. } \\
\text { Poor general health was positively related with } \\
\text { frequent health complains }\end{array}$ \\
\hline
\end{tabular}

$\begin{array}{ccccc}\text { Rahman et al. } & 2013 & \text { Saudi } & 650 & \text { Not specified }\end{array}$

Male students experience more stress than female students.

Academic performance and psychological issues were the main sources of stress for students.

\section{The PRISMA Flow Diagram of the Systematic Review}

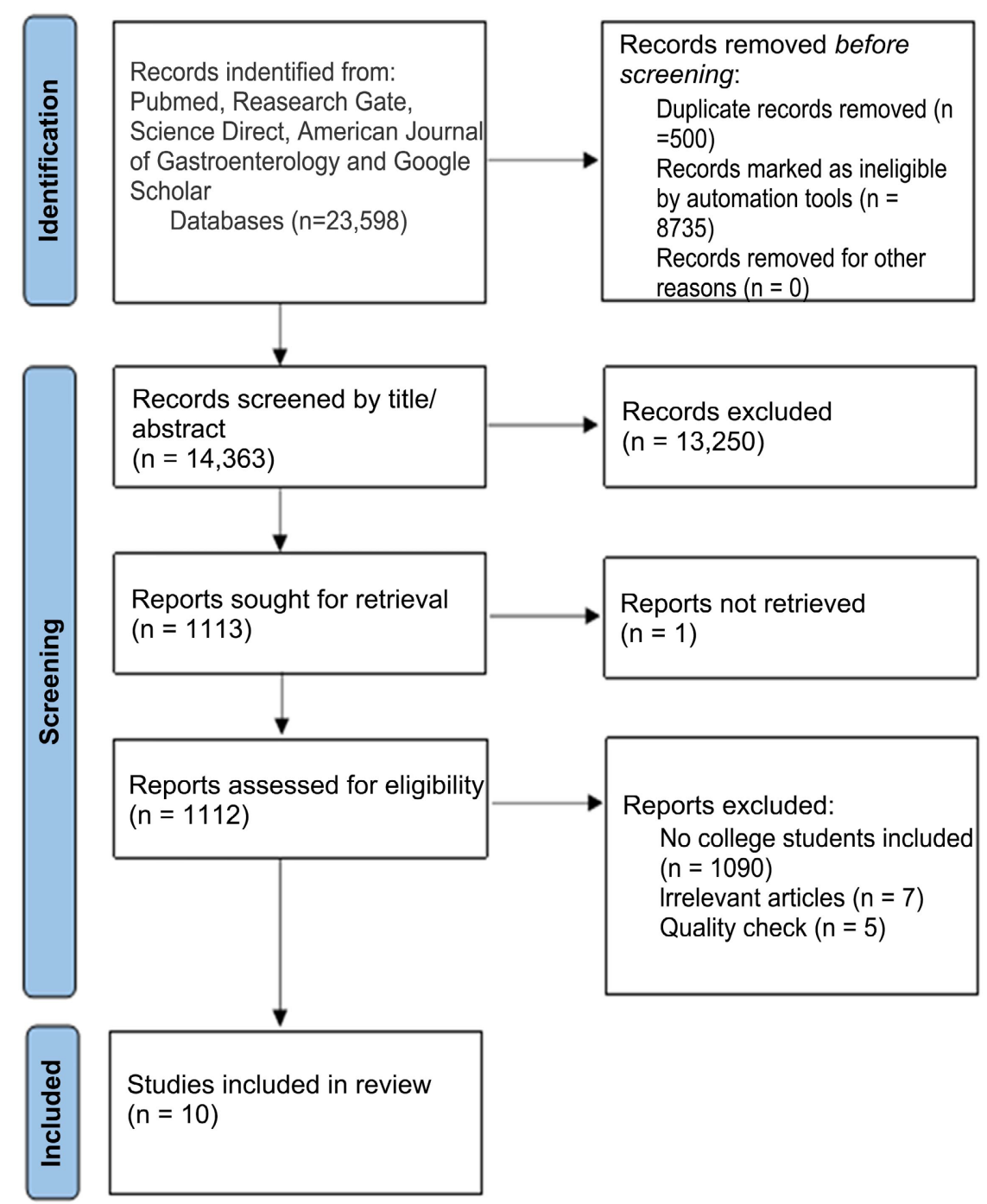

Figure 1. The PRISMA flow diagram of the systematic review. 
Table 4. The Newcastle Ottawa Scale for assessing the quality of cross-sectional studies.

\begin{tabular}{|c|c|c|c|c|c|c|c|c|c|c|}
\hline $\begin{array}{l}\text { Newcastle Ottawa criteria } \\
\text { (Yes, No, Uncertain) }\end{array}$ & $\begin{array}{l}\text { El Ansari } \\
\text { et al. [4] }\end{array}$ & $\begin{array}{c}\text { Lee } \\
\text { et al. [5] }\end{array}$ & $\begin{array}{l}\text { Jahan } \\
\text { et al. [7] }\end{array}$ & $\begin{array}{c}\text { Nur } \\
\text { et al. [8] }\end{array}$ & $\begin{array}{l}\text { Balmus } \\
\text { et al. [9] }\end{array}$ & $\begin{array}{c}\text { Chu } \\
\text { et al. }[10\end{array}$ & $\begin{array}{l}\text { Gomathi } \\
\text { ]et al. }[11]\end{array}$ & $\begin{array}{l}\text { i Awadalla } \\
\text { ]et al. [12]e }\end{array}$ & $\begin{array}{l}\text { Chu } \\
\text { et al. [13] }\end{array}$ & $\begin{array}{l}\text { Rahman } \\
\text { et al. }\end{array}$ \\
\hline $\begin{array}{l}\text { Representative of the exposed } \\
\text { cohort }\end{array}$ & Yes & Yes & Yes & Yes & Yes & Yes & Yes & Yes & Yes & Yes \\
\hline Selection of external control & No & No & No & No & Yes & No & No & No & No & No \\
\hline Ascertainment of exposure & Yes & Yes & Yes & Yes & Yes & Yes & Yes & Yes & Yes & Yes \\
\hline $\begin{array}{l}\text { The desired outcome is not } \\
\text { present at the start of the } \\
\text { investigation. }\end{array}$ & Yes & Yes & Yes & Yes & Yes & Yes & Yes & Yes & Yes & Yes \\
\hline $\begin{array}{l}\text { Comparability of the main } \\
\text { factor }\end{array}$ & Yes & Yes & Yes & Yes & Yes & Yes & Yes & Yes & Yes & Yes \\
\hline $\begin{array}{l}\text { Comparability of the } \\
\text { additional factor }\end{array}$ & Yes & Yes & Yes & No & No & No & No & Yes & Yes & Yes \\
\hline Assessment of outcome & Yes & Yes & Yes & Yes & Yes & Yes & Yes & Yes & Yes & Yes \\
\hline Enough time for follow-up & No & No & No & No & No & No & No & No & No & No \\
\hline Adequacy of follow up & Yes & Yes & Yes & Yes & Yes & Yes & Yes & Yes & Yes & Yes \\
\hline Evaluation & $7 / 9$ & $7 / 9$ & $7 / 9$ & $6 / 9$ & $7 / 9$ & $6 / 9$ & $6 / 9$ & $6 / 9$ & $7 / 9$ & $6 / 9$ \\
\hline
\end{tabular}

\subsection{Stressors in Students' Life}

Cause of stress, otherwise known as "stressors," are plenty in number in a student's life. Let it be in school or college; these stressors will play a part in a student's body, thoughts, and feelings. Gomathi et al. mention that academic, emotional, and health-related stressors are the three types of stressors [11]. "Frequency of exams," "academic burden," and "time management" are all part of the academic realm. The psychological domain, on the other hand, was primarily concerned with "future fears," "excessive parental expectations," "anxiety," and "working with members of the opposing gender." "Irregular eating habits," "lack of exercise," and "lack of a nutritious diet" were among the health-related domains [11]. Especially students living away from their families tend to skip meals or eat healthy [11].

Similarly, a study conducted in 2013 mentions that the main stressors among students are linked to academic performance and the psychosocial realm [2]. This study also mentions that Unsuitable teaching methods, an uncomfortable college study atmosphere, and the worry of failing exams are all possible sources of stress for college students [2]. Healthy eating habits, a positive mindset, and physical exercise are needed to perform well in college and keep stress at bay.

The stressors are explained in Figure 2.

\subsection{Frequency of Symptoms by the Perceived Stress Level}

In 2014, El Ansari et al. reported that the frequency of symptoms increased with perceived stress [4]. Based on quartile, perceived stress was divided into four levels. 


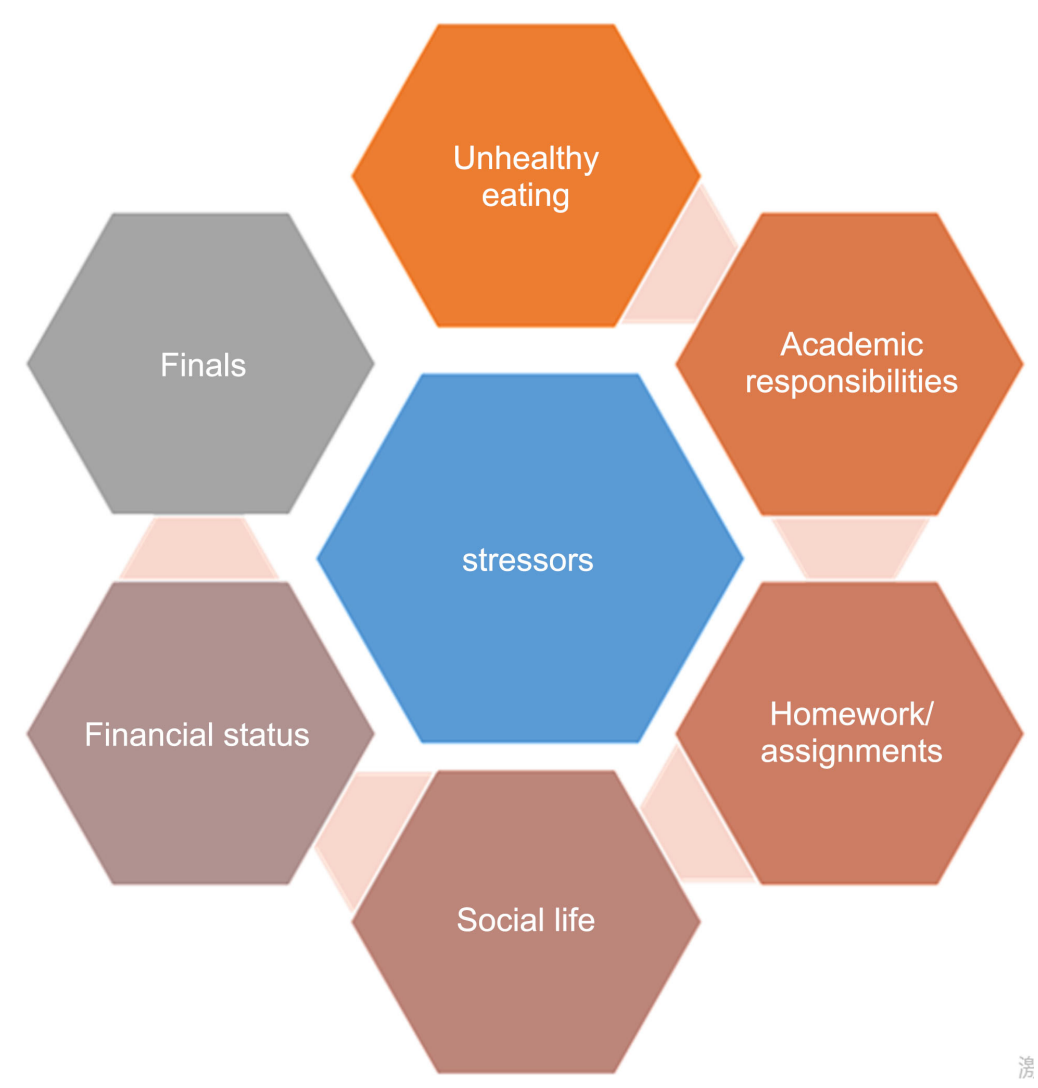

Figure 2. Stressors.

On a scale of one to four, the first quartile (Q1) had the lowest stress and symptoms and the fourth quartile (Q4) had the greatest. Students with Q4 level of stress, experienced almost 2 - 3 gastrointestinal symptoms more than Q1 [4]. Likewise, a cross-sectional study conducted in 2011 also noted a significant relationship between the increasing level of perceived stress and the number of gastrointestinal symptoms [5]. Seemingly gender had a role in the level of stress. In a recent study, female students reported having higher anxiety levels and specific symptoms such as inflammatory bowel syndrome [7]. In contrast, Rahman et al. specified in their study that males are exposed to higher levels of stress than females [14]. Since the study conducted in 2013 had a total of 650 participants and the study conducted years later in 2020 had only 81 participants, males could be more prone to high levels of stress as they have financial responsibility and need to finish their studies at an optimum time [7] [14].

Nevertheless, stress needs to be controlled in both males and females to avoid experiencing displeasing symptoms. And interestingly, with increasing age, the level of stress decreases [4] [9]. Younger students are believed to experience more stress than older students.

\subsection{Common Gastrointestinal Symptoms}

The gastrointestinal symptoms (Figure 3) can be classified as abdominal pain, esophageal, upper dysmotility, and bowel symptoms [7]. Esophageal symptoms 


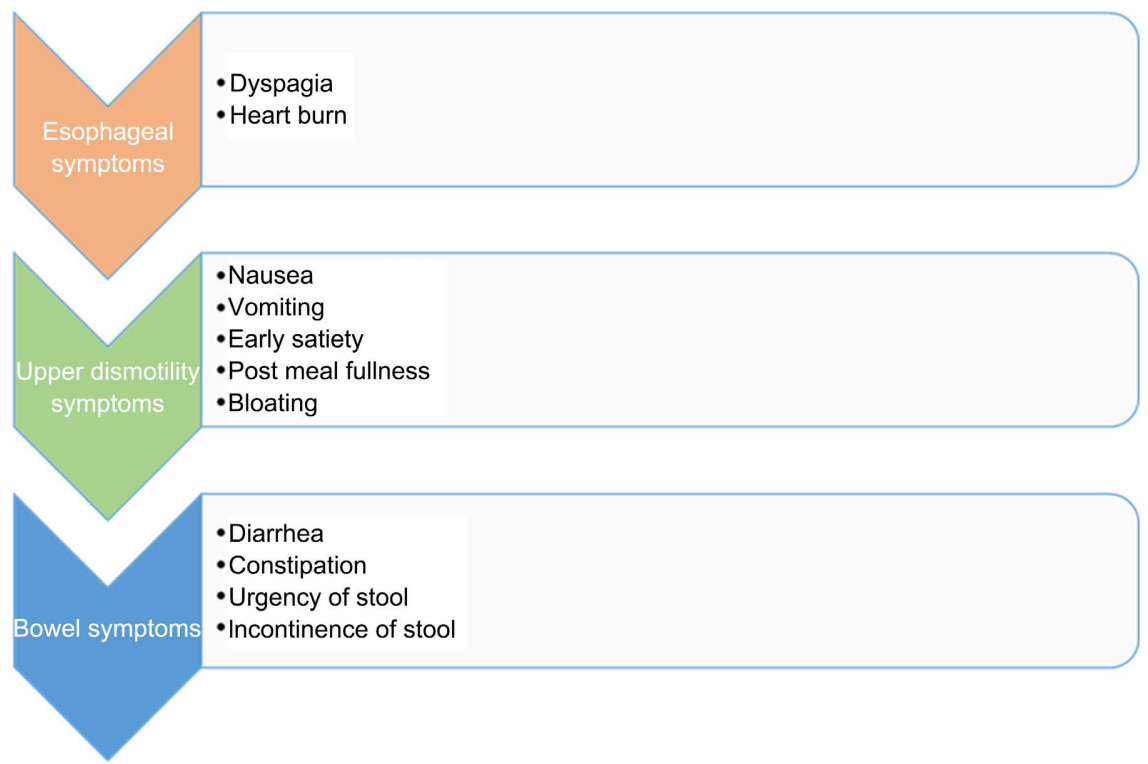

Figure 3. Gastrointestinal symptoms.

included dysphagia and heartburn, upper dysmotility symptoms: nausea, vomiting, early satiety, post-meal fullness in the abdomen, and bloating. Bowel symptoms are diarrhea, constipation, the urgency of stool, and stool incontinence [7]. According to the cross-sectional study conducted by Jahan et al., the most common symptoms experienced by students were post-meal fullness (34.6\%), bloating (37\%), abdominal pain (28.4\%), diarrhea (7.4\%), and constipation (28.4\%) [7]. In addition, another study mentions the common symptoms as postprandial fullness (91.3\%), bloating (88.9\%), abdominal pain (87.8\%) and diarrhea/constipation (84.7\%) [5]. Changes in stool frequency during a stressful time were also another observation made about gastrointestinal habits during stressful conditions [9].

It was also observed that females and male students experienced different symptoms. Females usually complained of inflammatory bowel syndrome, and males complained of symptoms related to gastroesophageal reflux disease [7] [12]. A study conducted in 2020 states that inflammatory bowel syndrome was $21 \%$ higher in females [7]. In contrast, Awadalla et al. report in their study that gastroesophageal reflux disease was higher in males [12]. The cause of reflux is that when exposed to stress, there is an increased release of gastric acid and a slow pace of gastric emptying [14].

\subsection{Asian vs. Western Students}

In the study by Chu et al., health complaints of students from German and Chinese universities were compared. Similarly, Ansari et al. compared the students from the UK and Egypt [4]. Both of these studies compared a country from Western Europe and Asia. The studies indicate that several factors like sociographic, lifestyle, religious beliefs, and cultural differences could contribute to the stress level in university students [13]. In addition, the nature of the study in 
the higher education system varies greatly between Asians and western countries [4]. In Egypt, traditionally, students enter universities right after finishing high school, and on the other hand, high school students in the UK take a gap year before applying for colleges [4]. This practice in the west helps students relax and catch their breath instead of rushing into college and adding to their stress levels. However, students of the west generally were older, consumed more alcohol, used illicit drugs, and smoked more than students of Asia [4] [13]. All these external factors could increase the chances of triggering certain health complaints, including gastrointestinal symptoms. Chu et al. reported that Chinese students complained of gastrointestinal symptoms more often than German students who had psychological symptoms [13]. It was also noted that students with a higher BMI had fewer gastrointestinal complaints among the Chinese students but had no significant association among the Germans [13]. It's evident through these studies that Asian students have higher levels of stress and complain more about gastrointestinal symptoms than the students of the west.

\subsection{Limitations}

One of the main limitations of the included studies is that all the studies are cross-sectional studies; hence no causal relationship can be derived. The stress reported by the students could have been a result of prevailing symptoms or vice versa, where the symptoms add to students' stress levels. Hence more clinical research is required to support this relationship. Although it was required that articles included being only specific to stress and gastrointestinal symptoms, some studies mentioned gastrointestinal symptoms under a general group termed as health complaints.

\section{Conclusion}

This systematic review aimed to emphasize the linkage between perceived stress and gastrointestinal symptoms in college students. The studies showed a positive link between stress and symptoms. And the higher the level of stress, the more is the number of symptoms. The most common gastrointestinal symptom associated with stress was post-meal fullness. Moreover, Female students are generally more stressed than males. Also, the goal of this study was to discover alternative ways to dilute the stress levels in students and reduce the intake of drugs. Some of the interventions that college students can follow are counseling, self-hypnosis, reducing alcohol consumption, meditation, avoiding skipping meals, and sleeping for a minimum of six hours.

\section{Conflicts of Interest}

The authors declare no conflicts of interest regarding the publication of this paper.

\section{References}

[1] Bouchrika, I. (2020) 50 Current Student Stress Statistics: 2020/2021 Data, Analysis 
\& Predictions. https://research.com/education/student-stress-statistics

[2] Yusoff, M.S.B., Abdul Rahim, A.F. and Yaacob, M.J. (2010) Prevalence and Sources of Stress among University Sains Malaysia Medical Students. Malaysian Journal of Medical Sciences, 17, 30-37.

[3] Reddy, K.J., Menon, K.R. and Thattil, A. (2018) Academic Stress and Its Sources among University Students. Biomedical and Pharmacology Journal, 11, 531-537. https://doi.org/10.13005/bpj/1404

[4] El Ansari, W., Oskrochi, R. and Haghgoo, G. (2014) Are Students' Symptoms and Health Complaints Associated with Perceived Stress at University? Perspectives from the United Kingdom and Egypt. International Journal of Environmental Research and Public Health, 11, 9981-10002. https://doi.org/10.3390/ijerph111009981

[5] Lee, E.Y., Mun, M.S., Lee, S.H. and Cho, H.S. (2011) Perceived Stress and Gastrointestinal Symptoms in Nursing Students in Korea: A Cross-Sectional Survey. BMC Nursing, 10, Article No. 22. https://doi.org/10.1186/1472-6955-10-22

[6] Norton, G.R., Norton, P.J., Asmundson, G.J., Thompson, L.A. and Larsen, D.K. (1999) Neurotic Butterflies in My Stomach: The Role of Anxiety, Anxiety Sensitivity and Depression in Functional Gastrointestinal Disorders. Journal of Psychosomatic Research, 47, 233-240. https://doi.org/10.1016/S0022-3999(99)00032-X

[7] Jahan, F., Siddiqui, M. and Aguiar, M. (2020) Correlation of Perceived Stress and GI symptoms in Medical Students in Oman. https://www.researchgate.net

[8] Nur, H.C.N. (2015) The Relationship between Perceived Stress and Gastrointestinal Symptoms in Nursing and Midwifery Students. TAF Preventive Medicine Bulletin, 14, 475-482. https://doi.org/10.5455/pmb.1-1434027488

[9] Balmus, I.M., Robea, M., Ciobica, A. and Timofte, D. (2019) Perceived Stress and Gastrointestinal Habits in College Students. Acta Endocrinologica (Copenhagen), 15, 274-275. https://doi.org/10.4183/aeb.2019.274

[10] Chu, L., Zhou, H., Lü, B., Li, M. and Chen, M.Y. (2012) An Epidemiological Study of Functional Bowel Disorders in Zhejiang College Students and Its Relationship with Psychological Factors. Chinese Journal of Internal Medicine, 51, 429-432.

[11] Gomathi, K.G., Ahmed, S. and Sreedharan, J. (2012) Psychological Health of First-Year Health Professional Students in a Medical University in the United Arab Emirates. Sultan Qaboos University Medical Journal, 12, 206-213. https://doi.org/10.12816/0003114

[12] Awadalla, N.J. (2019) Personal, Academic and Stress Correlates of Gastroesophageal Reflux Disease among College Students in Southwestern Saudi Arabia: A Cross-Section Study. Ann Med Surg (Lond), 47, 61-65. https://doi.org/10.1016/j.amsu.2019.10.009

[13] Chu, J.J., Khan, M.H., Jahn, H.J. and Kraemer, A. (2015) Comparison of Subjective Health Complaints between Chinese and German University Students: A CrossSectional Study. International Journal of Environmental Research and Public Health, 12, 15794-15806. https://doi.org/10.3390/ijerph121215019

[14] Abdel Rahman, A.G., Al Hashim, B.N., Al Hiji, N.K. and Al-Abbad, Z. (2013) Stress among Medical Saudi Students at College of Medicine, King Faisal University. Journal of Preventive Medicine and Hygiene, 54, 195-199. 